\title{
Transfusion Transmissible Infections Among Voluntary Blood Donors at Dessie Blood Bank, Northeast Ethiopia: Cross-Sectional Study
}

\author{
Edosa Kebede (iD) \\ Gashaw Getnet ${ }^{2}$ \\ Getie Enyew ${ }^{3}$ \\ Daniel Gebretsadik (D) \\ 'Department of Medical Laboratory \\ Science, College of Medicine and Health \\ Sciences, Wollo University, Dessie, \\ Ethiopia; ${ }^{2}$ Department of Medical \\ Laboratory Science, Family Guidance \\ Association of Ethiopia, Dessie Branch, \\ Dessie, Ethiopia; ${ }^{3}$ Department of Medical \\ Laboratory Science, Dr. Mehretie \\ Children's Speciality Clinic, Gondar. \\ Ethiopia
}

This article was published in the following Dove Press journal:

Infection and Drug Resistance

\begin{abstract}
Background: The prevalence of transfusion transmitted infections (TTIs) among blood donors varies across different geographical populations. Establishing the sero-prevalence of the disease among blood donors is important to informing the direction of preventive and control strategies.
\end{abstract}

Objective: The aim of this study was to determine the sero-prevalence of transfusion transmitted infections among voluntarily blood donors at Dessie Blood Bank, North East Ethiopia.

Methods and Materials: A cross-sectional study was conducted from November 10 to December 12, 2018. A total of 384 blood donors were conveniently included in this study. Socio-demographic data and other factors were collected using a pre-tested structured questionnaire. Five milliliters of venous blood was collected using a sterile test tube from each blood donor and the blood was allowed to clot; then, serum was separated by centrifugation for laboratory investigation. Serum samples from blood donors were tested by enzyme-linked immunosorbent assays (ELISA) for the presence of hepatits B surface antigen (HBsAg), and antibodies to human immunodeficiency virus (HIV-1/2), hepatits $\mathrm{C}$ virus (HCV), and Treponema pallidum. Logistic regression was used to explore risk factors associated with each transfusion transmissible infection.

Results: From a total of 384 blood donors, 24 (6.25\%) of them had serological evidence for at least one infection. The overall sero-prevalence rates of HBV, HCV, HIV, and syphilis among blood donors were $4.2 \%, 0 \%, 0.26 \%$, and $1.82 \%$, respectively. Educational status was significantly associated with HBV infection. Multiple sexual behaviors had statistically significant association with syphilis.

Conclusion: In conclusion, $6.25 \%$ of blood donors still harbor transfusion transmissible infections despite recent blood donation safety improvements with the greater majority $(4.2 \%)$ of cases caused by HBV infection.

Keywords: transfusion transmitted infections, HBV infection, syphilis, HCV infection, HIV infection, Ethiopia

\section{Introduction}

Blood transfusion is an effective treatment for saving millions of lives worldwide each year. However, unsafe transfusion leads to many life-threatening complications and increases the possibility of transfusion-transmitted infections (TTIs). ${ }^{1}$ The magnitude of this problem is directly related to the prevalence of TTIs among blood donors. $^{2}$
Correspondence: Edosa Kebede

Tel +251913811305

Email edexkebede@gmail.com
Infection and Drug Resistance 2020:13 4569-4576

4569

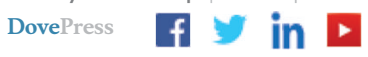

http://doi.org// 0.21 47//IDR.S287224 
In a country like Ethiopia, where national blood transfusion services and policies, appropriate infrastructure, trained personnel, and financial resources are inadequate, blood safety remains an issue of major concern in transfusion medicine. ${ }^{3}$ An essential requirement in the procurement of safe blood is to have a national program for donor selection, recruitment, retention, and education; this could limit disease transmissions to the recipients. Common TTIs are human immunodeficiency virus (HIV), hepatitis B virus (HBV), hepatitis $\mathrm{C}$ virus (HCV), and syphilis, because of their prolonged viraemia and carrier or latent state. ${ }^{4}$

The study on TTIs among blood donors is of paramount importance to evaluate the burden and risk factors for TTIs in the general population. ${ }^{5}$ The prevalence of TTIs among blood donors varies across the world, as well as within countries. In sub-Saharan Africa, about $0-1.1 \%$ of HIV infections were related with blood transfusion. ${ }^{6}$ TTIs can be transmitted from one infected individual to another during delivery, by unprotected sex, and by sharing needles. HBV is highly infectious and relatively easy to be transmitted and has a relatively higher prevalence in the tropics. ${ }^{7}$ According to various studies conducted in different part of Ethiopia ${ }^{3,-8-13}$ the overall sero-prevalence of TTIs was 2.4-29.5\%.

The World Health Organization (WHO) recommended the quality-assured screening of all donated blood for TTIs, including HIV, HBV, HCV, and syphilis, and this was adopted by the Ethiopian government for the provision of safe and efficacious blood and blood components. ${ }^{14}$ Accordingly, continuous evaluation of the burden of TTIs in blood donors is significant for estimating the risk of transfusion and enhancing donor selection strategies to reduce infectious diseases transmission. ${ }^{3}$

Even though, there are few epidemiological studies conducted in Ethiopia on TTIs among blood donors $^{3,-8-12}$ most of them are retrospective. Also, due to the lack of understanding, un-availability of screening tests, limited access to health facilities, and the unavailability of surveillance systems, the accurate figures of TTIs in our population are still unknown, particularly in this study area. Therefore, the aim of this study was to determine the sero-prevalence of TTIs among voluntarily blood donors at Dessie Blood Bank, North East Ethiopia.

\section{Methods and Materials}

\section{Study Area, Period, and Design}

A facility-based cross-sectional study was conducted at Dessie Blood Bank from November 10 up to
December 12, 2018. Dessie Blood Bank is found in Dessie town, South Wollo Zone, Amhara National Regional State, North Eastern Ethiopia. The town is located at a distance of $401 \mathrm{Km}$ from Addis Ababa, the capital city of Ethiopia. Its astronomical location is $11^{\circ} 8^{\prime} \mathrm{N}$ latitude and $39^{\circ} 38^{\prime} \mathrm{E}$ longitude.

\section{Study Population and Sampling Technique}

The study population was blood donors who were prospectively recruited in the study during the study period. To include blood donors who were eligible for donation, consented, interviewed, and gave blood for screening of TTIs, the convenient sampling technique was used. All participants who fulfilled the national and regional blood bank criteria were included and those who did not meet the inclusion criteria $(<50 \mathrm{Kg},<18$ years, $>65$ years, and unwillingness to give informed consent) were excluded from the study.

\section{Sample Size Determination}

The sample size was determined using sample size determination for estimation of a single population proportion formula and the following assumption was considered: $95 \%$ confidence interval $(\mathrm{Z} \alpha / 2=1.96), 50 \%$ proportion, and $5 \%$ margin of error.

$$
n=\frac{\left(z_{\alpha / 2}\right)^{2} * P(1-P)}{d^{2}}=384
$$

\section{Sample Collection and Laboratory Processing}

Socio-demographic data, and other factors were collected using interview by a pre-tested structured questionnaire. From each blood donor, $5 \mathrm{~mL}$ of venous blood was collected using a sterile test tube and it was allowed to clot, then serum was separated by centrifugation at a speed of 3 , 500 revolutions per minute for 5 minutes. The samples were screened for HIV-1 and -2 using a Vironostika HIV Uni-Form II Ag/Ab fourth generation ELISA (BioMerieux, Boxtel, Netherlands), HBsAg: a third generation ELISA, Hepanostika HBsAg UNi-Form II (Bio-Merieux), HCV: Human anti-HCV third generation ELISA (Human Gasellschaft for Bio-chemical and diagnostic $\mathrm{MbH}$, Germany), and syphilis by using WANTAI anti-TP ELISA (Bejieng wantai biological pharmacy). All tests were performed according to the manufacturer's instructions. 


\section{Data Analysis}

Epi-info version 3.5.1 was used to enter the data and it was transferred to SPSS version 20 software for analysis. Summary statistics such as frequencies and percentages were computed. The results were presented using words and tables. The binary logistic regression was used to assess the association between independent and dependent variables. The odds ratio and its $95 \%$ confidence interval (CI) were used to determine the strength of the association. A $P<0.05$ was taken as statistically significant.

\section{Data Quality Management}

Laboratory investigations were done by an experienced laboratory technologist with at least 2 years work experience. Standard operational procedures were strictly followed and quality control materials were used for all serological tests. Careful cleaning, coding, and entering of data were done.

\section{Ethical Considerations}

The study was conducted after ethical clearance was obtained from the Department of Medical Laboratory Sciences, College of Medicine and Health Sciences, Wollo University, and permission was also obtained from Dessie Blood Bank. Written informed consent was obtained from all study participants before data collection. Confidentiality of the study participants was also strictly maintained by using data without any personal identifier. Positive donors for any infection were informed and requested to visit health institutions. This study was fully conducted in accordance with the ethical consideration of the Declaration of Helsinki.

\section{Results}

\section{Socio-Demographic Characteristics of the Blood Donors}

A total of 384 blood donors participated in this study, and more than half of them $(213,55.5 \%$, and $217,56.5 \%)$ were male and aged 18-24, respectively. The median age of the donors was 23 years, with the range between $18-50$ years. The ajority $(274,71.4 \%)$ of the study participants were unmarried (Table 1).

\section{Sero-Prevalence of Transfusion Transmissible Infections}

From a total of 384 blood donors, 24 (6.25\%) had serological evidence for at least one infection. Hepatitis B virus was the most prevalent of the TTIs (16/384, 4.2\%) among
Table I Socio-Demographic Characteristics of Blood Donors at Dessie Blood Bank, North East Ethiopia, 2018

\begin{tabular}{|l|l|}
\hline Characteristics & N (\%) \\
\hline $\begin{array}{l}\text { Sex } \\
\text { Male }\end{array}$ & $213(55.5)$ \\
Female & $17 \mid(45.5)$ \\
\hline $\begin{array}{l}\text { Address } \\
\text { Rural } \\
\text { Urban }\end{array}$ & $40(10.4)$ \\
\hline $\begin{array}{l}\text { Age group } \\
\text { I8-24 } \\
25-34 \\
\geq 35\end{array}$ & $344(89.6)$ \\
\hline $\begin{array}{l}\text { Educational status } \\
\text { Illiterate } \\
\text { Literate }\end{array}$ & $217(56.5)$ \\
\hline $\begin{array}{l}\text { Occupation } \\
\text { Employed } \\
\text { Unemployed }\end{array}$ & $30(75.8)$ \\
\hline $\begin{array}{l}\text { Marital status } \\
\text { Unmarried } \\
\text { Married }\end{array}$ & $25(6.5)$ \\
\hline
\end{tabular}

blood donors. The overall sero-prevalence rates of HBV, $\mathrm{HCV}, \mathrm{HIV}$, and syphilis among blood donors were $4.2 \%$, $0 \%, 0.26 \%$, and $1.82 \%$, respectively. Among those who have the TTIs, $15 / 24(62.5 \%)$ were male, $15 / 24$ (62.5\%) were unemployed, 20/24 (83.3\%) were unmarried, 19/24 (79.1\%) were urban area dwellers, and 18/24 (75\%) were within the age group of 18-24 years.

\section{Prevalence and Associated Factors of HBV}

The overall sero-prevalence of HBV among blood donors was $16(4.2 \%)$. Its prevalence was 5.2\% among males and $2.9 \%$ among females (Table 2). The age-specific distribution of HBV infection revealed that a high prevalence among blood donors within the age group of 18-24 years shows $13(6 \%)$ and low prevalence $2(1.5 \%)$ among blood donors within the age group of 25-34 years. Regarding theeducational status of the blood donors, $3 / 25(12 \%)$ of the illiterate and 13/359 (3.6\%) of the literate had evidence of HBsAg sero-positivity (Table 2).

In binary logistic regression analysis only educational status was significantly associated with HBV infection. Those illiterate blood donors (AOR $=16.95,95 \%$ 
Table 2 Sero-Prevalence of HBV Infection Regarding Socio-Demographic Characteristics and Personal Behavior of Blood Donors at Dessie Blood Bank, North East Ethiopia, 2018

\begin{tabular}{|c|c|c|c|c|c|}
\hline \multirow[t]{2}{*}{ Variable } & HBV+ & \multirow[t]{2}{*}{ COR $(95 \% \mathrm{Cl})$} & \multirow[t]{2}{*}{$P$-value } & \multirow[t]{2}{*}{ AOR $(95 \% \mathrm{Cl})$} & \multirow[t]{2}{*}{ P-value } \\
\hline & n (\%) & & & & \\
\hline \multicolumn{6}{|l|}{ Sex } \\
\hline Male & $11 / 213(5.2)$ & I.8I (0.62-5.3I) & $0.28 \mathrm{I}$ & $0.728(0.178-2.98)$ & 0.659 \\
\hline Female & $5 / 17 \mid(2.9)$ & 1 & - & I & \\
\hline \multicolumn{6}{|l|}{ Address } \\
\hline Rural & $3 / 40(7.5)$ & $2.06(0.56-7.58)$ & 0.275 & $0.934(0.148-5.9)$ & 0.942 \\
\hline Urban & I3/344 (3.8) & 1 & - & 1 & \\
\hline \multicolumn{6}{|l|}{ Age group } \\
\hline 18-24 & $13 / 217(6)$ & $1.85(0.23-14.7)$ & 0.561 & $2.98(0.23-38.7)$ & 0.404 \\
\hline $25-34$ & $2 / 137$ (I.5) & $0.43(0.038-4.9)$ & 0.496 & $0.40(0.03-6.1)$ & 0.512 \\
\hline$\geq 35$ & $1 / 30(3.3)$ & 1 & - & 1 & \\
\hline \multicolumn{6}{|c|}{ Educational status } \\
\hline Illiterate & $3 / 25(12)$ & $3.63(0.96-13.7)$ & 0.057 & $16.95(1.66-172.9)$ & $0.017^{*}$ \\
\hline Literate & $13 / 359(3.6)$ & 1 & - & I & \\
\hline \multicolumn{6}{|l|}{ Occupation } \\
\hline Employed & $4 / 180(2.2)$ & $0.36(0.12-1.2)$ & 0.085 & $0.59(0.12-3.03)$ & 0.526 \\
\hline Unemployed & I2/204 (5.9) & 1 & - & I & \\
\hline \multicolumn{6}{|l|}{ Marital status } \\
\hline Unmarried & $14 / 274(5.1)$ & $2.91(0.65-13.01)$ & 0.163 & $1.94(0.26-14.5)$ & 0.517 \\
\hline Married & $2 / 110(1.8)$ & I & - & I & \\
\hline \multicolumn{6}{|c|}{ Multiple sexual behavior } \\
\hline Yes & $5 / 78(5.1)$ & $1.84(0.62-5.45)$ & 0.273 & $2.43(0.74-8.01)$ & 0.144 \\
\hline No & $11 / 306(3.6)$ & & - & 1 & \\
\hline \multicolumn{6}{|l|}{ Nose piercing } \\
\hline Yes & $1 / 24(4.2)$ & I (0.13-7.9) & 0.999 & $7.65(0.39-151.9)$ & 0.182 \\
\hline No & $15 / 360(4.2)$ & 1 & - & I & \\
\hline \multicolumn{6}{|l|}{ Ear piercing } \\
\hline Yes & 2/155 (1.3) & $4.98(1.12-22.24)$ & 0.035 & $0.093(0.009-0.93)$ & 0.043 \\
\hline No & $14 / 229(6.1)$ & 1 & - & I & \\
\hline
\end{tabular}

Note: *Significant values.

Abbreviations: $\mathrm{HBV}$, hepatitis $\mathrm{B}$ virus; $\mathrm{COR}$, crude odds ratio; $\mathrm{AOR}$, adjusted odds ratio; $\mathrm{Cl}$, confidence interval

$\mathrm{CI}=1.66-172.9, P=0.017)$ were at higher risk of HBV infection compared to the literate blood donors (Table 2).

\section{Prevalence and Associated Factors of Syphilis}

The sero-prevalence of syphilis among blood donors was $7 / 384(1.82 \%)$. The prevalence of syphilis was higher among male $(4,1.9 \%)$ blood donors compared with female (3, 1.75\%) donors. Regarding the age group, a high prevalence was observed among blood donors within the age group of 25-34 years, which showed 3 (2.2\%) (Table 3). In both bivariable and multivariable binary logistic regression analysis, having multiple sexual behavior was the only variable which showed a statistically significant association with syphilis. The odds of syphilis among those who had multiple sexual behavior were about 7-times higher than among those who had no multiple sex behavior $(\mathrm{AOR}=7.13$; $\mathrm{CI}=1.4-36.3)$ (Table 3).

\section{Discussion}

Blood transfusion is considered to be a potential risk factor for the transmission of blood-borne infections such as HBV, HCV, HIV, and syphilis, which are the greatest threats to blood safety for the recipient. The 
Table 3 Sero-Prevalence of Syphilis Infection Regarding Socio-Demographic Characteristics and Personal Behavior of Blood Donors at Dessie Blood Bank, North East Ethiopia 2018

\begin{tabular}{|c|c|c|c|c|c|}
\hline \multirow[t]{2}{*}{ Variable } & Syphilis+ & \multirow[t]{2}{*}{ COR $(95 \% \mathrm{Cl})$} & \multirow[t]{2}{*}{$P$-value } & \multirow[t]{2}{*}{ AOR $(95 \% \mathrm{Cl})$} & \multirow[t]{2}{*}{$P$-value } \\
\hline & n (\%) & & & & \\
\hline \multicolumn{6}{|l|}{ Sex } \\
\hline Male & $4 / 213(1.9)$ & $1.07(0.24-4.9)$ & 0.928 & $0.94(0.187-4.8)$ & 0.944 \\
\hline Female & 3/17I (I.75) & I & & 1 & \\
\hline \multicolumn{6}{|l|}{ Address } \\
\hline Rural & $\mathrm{I} / 40(2.5)$ & $1.44(0.17-12.3)$ & 0.737 & $1.04(0.099-10.9)$ & 0.974 \\
\hline Urban & 6/344 (I.74) & 1 & & I & \\
\hline \multicolumn{6}{|l|}{ Age group } \\
\hline 18-24 & $4 / 217(1.84)$ & 1 & & I & \\
\hline $25-34$ & $3 / 137(2.2)$ & $1.19(0.26-5.41)$ & 0.820 & $0.27(0.035-2.08)$ & 0.210 \\
\hline$\geq 35$ & 0 & & 0.998 & & 0.998 \\
\hline \multicolumn{6}{|l|}{ Educational status } \\
\hline Illiterate & $1 / 25(4)$ & $2.45(0.28-21.2)$ & 0.415 & $2.69(0.2 \mathrm{I}-35.5)$ & $0.45 I$ \\
\hline Literate & $6 / 359(1.67)$ & 1 & & 1 & \\
\hline \multicolumn{6}{|l|}{ Occupation } \\
\hline Employed & $5 / 180(2.8)$ & $2.89(0.55-15.06)$ & 0.209 & $5.22(0.74-36.8)$ & 0.097 \\
\hline Unemployed & $2 / 204(0.98)$ & 1 & & 1 & \\
\hline \multicolumn{6}{|l|}{ Marital status } \\
\hline Unmarried & $5 / 274(1.8)$ & $1.004(0.19-5.3)$ & 0.996 & $0.973(0.13-7.4)$ & 0.979 \\
\hline Married & $2 / 110(1.8)$ & I & & I & \\
\hline \multicolumn{6}{|l|}{ Multiple sexual behavior } \\
\hline Yes & $4 / 78(5.1)$ & $5.46(1.2-24.9)$ & $0.028^{*}$ & $7.13(1.4-36.3)$ & $0.018^{*}$ \\
\hline No & $3 / 306(0.98)$ & I & & 1 & \\
\hline
\end{tabular}

Note: *Significant values.

Abbreviations: $\mathrm{COR}$, crude odds ratio; $\mathrm{AOR}$, adjusted odds ratio; $\mathrm{Cl}$, confidence interval.

current study tried to show the sero-prevalence of TTI among blood donors at Dessie blood bank, Ethiopia. In the current study, the overall sero-prevalence of TTIs was $24(6.25 \%)$. The finding is consistent with previous reports from different parts of Ethiopia, such as Bahir Dar $(6 \%),{ }^{9}$ Gondar $(6.55 \%),{ }^{10}$ Hawassa $(7 \%),{ }^{11}$ and Dire Dawa (7.06\%). ${ }^{12}$ However, this finding is lower compared to other studies conducted in different parts of the country, such as Eastern Ethiopia (12.4\%), ${ }^{15}$ Jijiga (11.5\%), ${ }^{16}$ Gondar $(9.5 \%){ }^{3}$ and Wolaita Sodo $(29.5 \%) .{ }^{13}$ Similarly, it is also lower than reports from different areas of Africasuch as Eritrea $(12.9 \%),{ }^{17}$ Kenya $(14.1 \%),{ }^{18}$ Burkina Faso $(24.0 \%),{ }^{19}$ and Cameroon $(13.7 \%) .{ }^{20}$ In another way, the sero-prevalence finding in the current study is slight higher as compared to previous reports from different parts of Ethiopia, such as Debre Tabor $(4.6 \%),{ }^{21}$ and North Shoa, central Ethiopia (2.4\%). ${ }^{8}$ Likewise, the rate of TTIs in the current study is somehow higher than different research reports from other countries, like Eritrea (3.6\%), ${ }^{22}$ Ghana (4.06\%), ${ }^{23}$ India (4.36\%), ${ }^{24}$ and Pakistan (5.8\%). ${ }^{1}$ The possible reasons for the discrepancy in the total sero-prevalence of TTIs between various studies could be variation in the total sample size, in the nature of the study population, research method used, time period, the test kits on the market, storage, and validation of the test kits.

Donors with a sero-positive result for HBV in the current study totalled 16 (4.2\%), which is comparable with reports in Hawassa, Ethiopia (4.8\%), ${ }^{11}$ Gondar (4.7\% and 3.6\%), ${ }^{3,10}$ Bahir Dar (3.9\%), ${ }^{9}$ and Dire Dawa $(3.73 \%){ }^{25}$ But it is higher than reports from Pakistan $(1.84 \%),{ }^{1}$ Debre Tabor $(2.76 \%),{ }^{21}$ and India $(1.61 \%) .{ }^{24}$ On the other hand, as compared to reports from other studies in Wolaita Sodo $(9.5 \%)^{13}$ and in Ghana $(9.6 \%),{ }^{26}$ the sero-prevalence in the current study is low. The variation in the sero-prevalence across studies might be due to 
differences in socio-demographic, cultural and societal behavior, socio-economic status, and awareness of the population. In addition, methods of laboratory diagnosis used for screening can also be possible reasons.

According to the current study, illiterate blood donors (AOR=16.95, 95\% CI=1.66-172.9, $P=0.017$ ) were more likely to have HBV infection compared to literate donors. The relatively higher HBV sero-positivity among the illiterate might be attributed to poor awareness regarding mode of transmission due to their low educational status in which these individuals might have sexual contact and share sharp materials with a person infected with these type of TTI.

In our study, the sero-prevalence of HIV among blood donors was $0.26 \%$, which is lower compared to previous studies conducted in Ethiopia $\left(3.8 \%{ }^{3} \text { and } 2.24 \%\right)^{10}$ and elsewhere in the world, like $1.4 \%$ in Nigeria ${ }^{27}$ and $1 \%$ reported in Cameroon. ${ }^{28}$ However the finding is comparable with previous studies from other countries such as India $\left(0.32 \%,{ }^{24} 0.6 \%,{ }^{29} 0.2 \%,{ }^{30}\right.$ and $\left.0.34 \%\right),{ }^{31}$ Pakistan $(0.04 \%),{ }^{1}$ China $(0.31 \%),{ }^{4}$ and other parts of Ethiopia, specifically North Shoa $(0.25 \%),{ }^{8}$ and Harar $(0.6 \%) .{ }^{32}$ These variations could also be due to actual changes in population risks or effectiveness of donor screening measures.

The prevalence of HCV infection among blood donors in this study was $0.00 \%$, which is slightly comparable with previous studies $(0.2 \%)$ in south west Ethiopia ${ }^{33}$ and elsewhere in the world; $0.06 \%$ in Pakistan, ${ }^{34}$ and $0.03 \%$ in Bangladesh. ${ }^{35}$ On the other hand, this finding is much lower than previous studies done in Nigeria $(2.5 \%)^{27}$ and Kenya $(3.21 \%){ }^{36}$ The wide variations of $\mathrm{HCV}$ seroprevalence in different studies might be due to differences in risk behaviors such as injecting drug use and sharing objects for skin piercing between different geographical areas, use of different methods for testing, and use of different generation of ELISA test kits, having different sensitivities and specificities and use of different sample size.

The overall (1.82\%) sero-prevalence of syphlis in this study is consistent to previous reports like $1.3 \%$ in Gondar, ${ }^{3} 1.2 \%$ in Bahir Dar, ${ }^{9} 1.45 \%$ in India, ${ }^{30}$ and $1.56 \%$ in Kenya. ${ }^{36}$ However, it is lower than the $7.9 \%$ in Wolaita $\mathrm{Sodo}^{13}$ and $8.1 \%$ in Cameroon, ${ }^{20}$ but is higher than the $0.74 \%$ in Debre Tabor, ${ }^{21}$ the $0.5 \%$ in Hawassa, ${ }^{11}$ the $0.71 \%$ in North Shoa, ${ }^{8}$ the $0.6 \%$ in Eritrea, ${ }^{22}$ and the $0.05 \%$ in India. ${ }^{29}$ Variation observed in sero-prevalence may be attributed to differences in geographical setting, sample size, and use of different methods for testing. In this study multiple sexual behavior was significantly associated with higher risk of syphilis ( $\mathrm{AOR}=7.13,95 \%$ $\mathrm{CI}=1.4-36.3, P=0.018$ ). This could be due to poor awareness about sexually transmitted diseases.

\section{Limitation of the Study}

These findings may, however, not precisely reflect the prevalence of the blood donor population due to the donor selection processes involved. Another weakness may be associated with intrinsic weakness of the diagnostic test used in this study use of serological and it would be better if nucleic acid based techniques had been used. Therefore, the results reported in this study may underestimate (presence of a window period) the frequency of TTIs among donors in this population. Another concern is the question on sex life style is associated with stigma, with a possibility of influence on overall risk estimate.

\section{Conclusion and Recommendations}

In conclusion, $6.25 \%$ of blood donors still harbor transfusion transmissible infections despite recent blood donation safety improvements with the greater majority (4.2\%) cases caused by HBV infection. Promoting awareness creation regarding transmission of TTIs and early uptake of HBV screening test with subsequent vaccination would help reduce TTIs burden observed among blood donors. Further prospective studies should be conducted rigorously with advanced methods and a large sample size.

\section{Abbreviations}

HBV, hepatitis B virus; HCV, hepatitis C virus; HIV, human immunodeficiency virus; TTIs, transfusion-transmissible infections; WHO, World Health Organization.

\section{Data Sharing Statement}

The data that support the findings of this study are available upon reasonable request from the corresponding author.

\section{Acknowledgments}

The authors would like to thank members of the Dessie Blood Bank Service for assisting in laboratory investigation by providing the test material. We also acknowledge study participants for their cooperation in providing genuine responses. 


\section{Author Contributions}

All authors made substantial contributions to the conception and design, involved in data collection and laboratory work, data analysis, drafting, or revising the article, have agreed on the journal to which the article will be submitted, gave final approval of the version to be published, and agree to be accountable for all aspects of the work.

\section{Funding}

The authors did not receive any funding for this study.

\section{Disclosure}

The authors declare that they have no conflicts of interest.

\section{References}

1. Arshad A, Borhany M, Anwar N, et al. Prevalence of transfusion transmissible infections in blood donors of Pakistan. BMC Hematol. 2016;16:27. doi:10.1186/s12878-016-0068-2

2. Apata IW, Averhoff F, Pitman J, et al. Progress toward prevention of transfusion-transmitted hepatitis B and hepatitis C infection-subSaharan Africa, 2000-2011. MMWR Morb Mortal Wkly Rep. 2014;63(29):613.

3. Tessema B, Yismaw G, Kassu A, et al. Seroprevalence of HIV, HBV, $\mathrm{HCV}$ and syphilis infections among blood donors at Gondar University Teaching Hospital, Northwest Ethiopia: declining trends over a period of five years. BMC Infect Dis. 2010;10(1):111. doi:10.1186/1471-2334-10-111

4. Song Y, Bian Y, Petzold M, Ung CO. Prevalence and trend of major transfusion-transmissible infections among blood donors in Western China, 2005 through 2010. PLoS One. 2014;9(4):e94528. doi:10. 1371/journal.pone.0094528

5. Gharehbaghian A. An estimate of transfusion-transmitted infection prevalence in general populations. Hepat Mon. 2011;11(12):1002 doi:10.5812/kowsar.1735143X.4144

6. Morar MM, Pitman JP, McFarland W, Bloch EM. The contribution of unsafe blood transfusion to human immunodeficiency virus incidence in sub-Saharan Africa: reexamination of the $5 \%$ to $10 \%$ convention. Transfusion. 2016;56(12):3121-3132. doi:10.1111/trf.13816

7. Ogbu O, Uneke C. Hepatitis B virus and blood transfusion safety in sub-Saharan Africa. Internet J Infect Dis. 2009;7:2.

8. Deressa T, Birhan W, Enawgaw B, et al. Proportion and predictors of transfusion-transmissible infections among blood donors in North Shewa Zone, Central North Ethiopia. PLoS One. 2018;13(3): e0194083. doi:10.1371/journal.pone.0194083

9. Shiferaw E, Tadilo W, Melkie I, Shiferaw M. Sero-prevalence and trends of transfusion-transmissible infections among blood donors a Bahir Dar district blood bank, northwest Ethiopia: A four year retrospective study. PLoS One. 2019;14(4):e0214755. doi:10.1371/journal.pone. 0214755

10. Biadgo B, Shiferaw E, Woldu B, Alene KA, Melku M. Transfusiontransmissible viral infections among blood donors at the North Gondar district blood bank, northwest Ethiopia: A three year retrospective study. PLoS One. 2017;12(7):e0180416. doi:10.1371/journal.pone. 0180416

11. Birhaneselassie M. Prevalence of transfusion-transmissible infections in donors to an ethiopian blood bank between 2009 and 2013 and donation factors that would improve the safety of the blood supply in underdeveloped countries. Lab Med. 2016;47(2):134-139. doi:10. 1093/labmed/lmw003
12. Ataro Z, Urgessa F, Wasihun T. Prevalence and trends of major transfusion transmissible infections among blood donors in dire dawa blood bank, Eastern Ethiopia: retrospective study. Ethiop $J$ Health Sci. 2018;28(6):701-710.

13. Bisetegen FS, Bekele FB, Ageru TA, Wada FW. Transfusiontransmissible infections among voluntary blood donors at wolaita sodo university teaching referral hospital, South Ethiopia. Canadian j Infectious Diseases Med Microbiol. 2016;2016:8254343.

14. Organization WH. Blood Donor Selection: Guidelines on Assessing Donor Suitability for Blood Donation. World Health Organization; 2012.

15. Heyredin I, Mengistie B, Weldegebreal F. Sero-prevalence of transfusion-transmittable infections and associated factors among blood donors in Eastern Ethiopia: an Institutional-based cross-sectional study. SAGE Open Med. 2019;7:2050312119834468. doi:10.1177/2050312119834468

16. Mohammed Y, Bekele A. Seroprevalence of transfusion transmitted infection among blood donors at Jijiga blood bank, Eastern Ethiopia: retrospective 4 years study. BMC Res Notes. 2016;9(1):129. doi:10.1186/s13104-016-1925-6

17. Keleta YT, Achila OO, Haile AW, et al. Seroprevalence of transfusion transmitted infections among blood donors in gash barka zonal blood transfusion center, Barentu, Eritrea, 2014 through 2017. BMC Hematol. 2019;19:5. doi:10.1186/s12878-019-0136-5

18. Bartonjo G, Oundo J. Prevalence and associated risk factors of transfusion transmissible infections among blood donors at regional blood transfusion center nakuru and tenwek mission hospital, Kenya. Pan Afr Med J. 2019;34.

19. Nagalo BM, Bisseye C, Sanou M, et al. Seroprevalence and incidence of transfusion-transmitted infectious diseases among blood donors from regional blood transfusion centres in Burkina Faso, West Africa. Tropical Med Int Health. 2012;17(2):247-253. doi:10.1111/ j.1365-3156.2011.02902.x

20. Moukoko CEE, Sack FN, Same EGE, Mbangue M, Lehman LG. HIV, HBV, HCV and T. palliduminfections among blood donors and Transfusion-related complications among recipients at the Laquintinie hospital in Douala, Cameroon. BMC Hematol. 2014;14 (1):5. doi:10.1186/2052-1839-14-5

21. Birhane S, Abebaw S, Digissie A. Transfusion-transmissible infections among voluntary blood donors at debre tabor blood bank, north west ethiopia: a three years retrospective study. Health Care. 2018;06:04.

22. Siraj N, Achila OO, Issac J, et al. Seroprevalence of transfusion-transmissible infections among blood donors at national blood transfusion service, Eritrea: a seven-year retrospective study. BMC Infect Dis. 2018;18(1):264. doi:10.1186/s12879-018-3174-x

23. Lokpo SY, Dakorah MP, Norgbe GK, et al. The burden and trend of blood-borne pathogens among asymptomatic adult population in Akwatia: a retrospective study at the St. Dominic Hospital, Ghana. J Trop Med. 2017;2017:1-7. doi:10.1155/2017/3452513

24. Rawat A, Diwaker P, Gogoi P, Singh B. Seroprevalence \& changing trends of transfusion-transmitted infections amongst blood donors in a regional blood transfusion centre in north India. Indian J Med Res. 2017;146(5):642-645.

25. Habte Y, Seyoum B, Alemayehu T. Hepatitis b virus infection and associated factors among blood donors at Dire Dawa, Eastern Ethiopia. J Antivir Antiretrovir. 2016;08:04. doi:10.4172/jaa.100 0144

26. Walana W, Ahiaba S, Hokey P, et al. Sero-prevalence of HIV, HBV and HCV among blood donors in the kintampo municipal hospital, Ghana. British Microbiol Res J. 2014;4(12):1491-1499. doi:10.9734/ BMRJ/2014/12160

27. Oluwayemisi OH, Olasunkanmi SA, Kehinde OM. Prevalence of some transfusion-transmissible infections among first time and repeat voluntary and family replacement donors in north central nigeria. Sudan Medical Journal. 2016; 52(3):131-136. 
28. Nansseu JR, Mbogning DM, Monamele GC, et al. Sero-epidemiology of human immunodeficiency virus, hepatitis $\mathrm{B}$ virus and hepatitis $\mathrm{C}$ virus: a cross-sectional survey in a rural setting of the West region of Cameroon. Pan Afr Med J. 2017;28:201. doi:10.11604/pamj.2017. 28.201.12717

29. Meena S, Maheshwari V, Gupta D. Seroprevalence and trends of transfusion transmissible infections among voluntary and replacement donors-an institutional retrospective study. Tropical J Pathol Microbiol. 2018;4(4):330-335. doi:10.17511/jopm.2018.i04.06

30. Pathak C, Sehgal S. Evaluation of the seroprevalence of transfusion transmissible infections among blood donors in a tertiary care hospital of North India. Iranian J Blood Cancer. 2016;8(1):13-16.

31. Vandana WV, Rani KL. Transfusion transmitted infections among blood donors at a tertiary care teaching hospital in South India. Int J Microbiol Mycol. 2017;6(1):24-31.

32. Teklemariam Z, Mitiku H, Weldegebreal F. Seroprevalence and trends of transfusion transmitted infections at Harar blood bank in Harari regional state, Eastern Ethiopia: eight years retrospective study. BMC Hematol. 2018;18:24. doi:10.1186/s12878-018-0115-2
33. Kebede W, Mekonnen Z, Gerbi A, Abebe G. Transfusiontransmissible infection surveillance among blood donors in Southwest Ethiopia: A six years retrospective study. Asian Pacific J Tropical Disease. 2017;7(3):156-161. doi:10.12980/apjtd.7.201 7D6-384

34. Attaullah S, Khan S, Khan J. Trend of transfusion transmitted infections frequency in blood donors: provide a road map for its prevention and control. J Transl Med. 2012;10(1):20. doi:10.1186/ 1479-5876-10-20

35. Alom ST, Mondal KJ, Tarafder S, Sonia FA, Chowdhury PK, Islam MS. Sero-prevalence of transfusion transmissible infections among voluntary blood donors of Khulna Medical College Hospital. Bangladesh Med J. 2017;46(2):16-21. doi:10.3329/bmj.v46i2.40212

36. Onyango CG, Ogonda L, Guyah B, et al. Seroprevalence and determinants of transfusion transmissible infections among voluntary blood donors in Homabay, Kisumu and Siaya counties in western Kenya. BMC Res Notes. 2018;11(1):171. doi:10.1186/s13104-0183276-y

\section{Publish your work in this journal}

Infection and Drug Resistance is an international, peer-reviewed openaccess journal that focuses on the optimal treatment of infection (bacterial, fungal and viral) and the development and institution of preventive strategies to minimize the development and spread of resistance. The journal is specifically concerned with the epidemiology of antibiotic resistance and the mechanisms of resistance development and diffusion in both hospitals and the community. The manuscript management system is completely online and includes a very quick and fair peerreview system, which is all easy to use. Visit http://www.dovepress.com/ testimonials.php to read real quotes from published authors. 